\title{
Sistem Pendukung Keputusan Penentuan Strategi Pemasaran Barang dengan Metode Analytic Hierarchy Process
}

\author{
Ety Liani Putri ${ }^{* 1}$, Bosker Sinaga ${ }^{2}$ \\ 1,2Teknik Informatika, STMIK Pelita Nusantara, Indonesia \\ Email: ${ }^{1}$ etylianip@gmail.com, ${ }^{2}$ boskersinaga@gmail.com
}

\begin{abstract}
Abstrak
Untuk dapat memenangkan persaingan pasar, perusahaan menggunakan strategi pemasaran yang tepat agar dapat bertahan dan memenangkan pasar. Perusahaan yang baru berkembang perlu menyusun aturan layanan pemasaran untuk keberlanjutan perusahaan yang mampu bersaing secara mutu maupun kualitas. Sebagai perusahaan ecommerce yang baru berkembang PT. Prisma Mas Semesta memerlukan strategi pemasaran yang mampu membantu pengambil keputusan agar dapat memperkenalkan produk maupun jasa pada masyarakat. Metode yang digunakan untuk menganalisis penentuan strategi pemasaran barang menerapkan metode Analytic Hierarchy Process. Data penelitan dikumpulkan dari perusahaan penjualan barang online PT. Prisma Mas Semesta website duniadapur.co.id. Dalam menentukan strategi pemasaran barang terdapat 6 kelompok kriteria yaitu Managerial Capabilities, Customer Linking Capabilities, Market Innovation Capabilities, Human Resource Assets, Capabilities In Product Distribution, dan Reputational Assets. Berdasarkan perhitungan metode AHP, nilai Eigen kriteria dan alternatif diperoleh hasil perangkingan yaitu Differentiation Strategy memiliki nilai preferensi 0.59 sebagai Ranking 1, Cost Leadership Strategy memiliki nilai preferensi 0. 274 sebagai Ranking 2, dan Market Segmentation Strategies nilai preferensi sebesar 0.136 sebagai Ranking 3. Dapat disimpulkan bahwa alternatif yang berada di peringkat atas adalah Cost Leadership Strategy dengan nilai 0.59. Dalam strategi ini Dunia Dapur berusaha menekan biaya produksi, sehingga laba bersih dapat menguntungkan yang akan meningkatkan angka penjualan dan market share.
\end{abstract}

Kata kunci: Metode AHP, Nilai Preferensi, Perangkingan, Strategi Pemasaran, SPK

\begin{abstract}
To be able to win market competition, companies continuously find and use the right marketing strategies in order to survive and win the market. This newly developed company needs to formulate rules for marketing services for the sustainability of companies that are able to compete in terms of quality and quality. As a newly developing e-commerce company, PT. Prisma Mas Semesta requires a marketing strategy that can help decision makers to introduce products and services to the public. The method used to analyze the determination of the marketing strategy of goods applies the Analytic Hierarchy Process method. The research data was collected from the online goods sales company PT. Prisma Mas Semesta website duniadapur.co.id. In determining the marketing strategy of goods, there are 6 groups of criteria, namely Managerial Capabilities, Customer Linking Capabilities, Market Innovation Capabilities, Human Resource Assets, Capabilities In Product Distribution, and Reputational Assets. Based on the calculation of the AHP method, the eigenvalues of criteria and alternatives obtained ranking results, namely Differentiation Strategy has a preference value of 0.59 as Rank 1, Cost Leadership Strategy has a preference value of 0.274 as Rank 2, and Market Segmentation Strategies a preference value of 0.136 as Rank 3. Can it is concluded that the alternative that is ranked at the top is the Cost Leadership Strategy with a value of 0.59. In this strategy, Dunia Dapur tries to reduce production costs, so that net profit can be profitable which will increase sales and market share.
\end{abstract}

Keywords: AHP Method, DSS, Marketing Strategy, Preference Value, Ranking

\section{PENDAHULUAN}

Perusahaan diharapkan mampu bersaing dengan perusahaan lain yang memasarkan produk yang sama dan mampu mengolah perusahaan dengan baik. Pengelolaan dilakukan dari berbagai aspek bisnis perusahaan seperti melihat peta pasar yang sedang dihadapi, membuat pelanggan tetap memilih 
dan memberi kepercayaan terhadap perusahaan sehingga konsumen tidak memihak kepada perusahaan lain yang menawarkan produk serupa [1]. Terdapat dua faktor yang harus diperhatikan perusahaan dalam memaskarkan produk atau jasa yaitu faktor internal dan faktor eksternal. Manajemen perusahaan dapat menentukan strategi yang akan digunakan dengan mencocokkan sumber daya dan kemampuan manajemen perusahaan melihat kondisi eksternal perusahaan, baik kondisi pasar dan juga kondisi perusahaan pesaing. Menentukan strategi pemasaran yang tepat merupakan multi criteria problem karena melibatkan banyak kriteria [2]. Pengambil keputusan harus mempertimbangkan banyak faktor yang kompleks serta harus mengevaluasi dan dapat memilih strategi pemasaran yang tepat untuk kelangsungan bisnis perusahaan [3]. Pengambilan keputusan dari permasalahan yang multi criteria, dapat dilakukan dengan membangun sistem pendukung keputusan.

Sistem Pendukung Keputusan akan membantu manajemen perusahaan dalam menentukan strategi pemasaran menggunakan langkah-langkah dan konversi fakta-fakta menjadi nilai-nilai yang objektif [4]. Salah satu metode pengambilan keputusan yang dapat menyelesaikan permasalahan yang multi criteria adalah AHP (Analytic Hierarchy Process). AHP merupakan metode analisis keputusan dengan multi criteria untuk memecahkan permasalahan yang kompleks dan tidak terstuktur dengan cara mengubahnya dalam bentuk terstruktur yang memiliki banyak level sesuai kelompok [5].

PT. Prisma Mas Semesta merupakan perusahaan penjualanan barang peralatan dan perlengkapan dapur secara offline dan menambah aktivitas penjualanan online. Dengan membangun e-commerce yang dapat diakses melalui website www.duniadapur.co.id dan aplikasi android. Sebagai e-commercee yang baru didirikan, manajemen PT. Prisma Mas Semesta pada duniadapur.co.id perlu menyesuaikan strategi pemasaran yang tepat [6]. Pelanggan menginginkan sebuah produk sebagai produk yang tak tertandingi dan tidak serupa, sehingga memunculkan harga menjadi tidak dapat dikurangi dan pelanggan bersikap menjadi peduli ingin brand terlaris. Akan tetapi strategi ini dipersiakan tambahan biaya terkait dengan biaya penciptaan fitur produk yang lain namun berkualitas untuk itu perlu pengaturan strategi premium [7].

Penelitian Rekayasa SPK Lomba Desa Tingkat Kabupaten dengan Metode Analytical Hierarchy Process menjelaskan keputusan yang berasal dari multi kriteria atribut berkembang dengan baik dan memerlukan dasar matetika yang kuat [8]. Penelitian bagian dari SPK yaitu AHP digunakan untuk menunjang keputusan penilaian kinerja kerja karyawan SPBU menjelaskan penelitian dilakukan untuk mengumpulkan data alternatif keputusan untuk menyelesaikan permasalahan yang muncul, perlu dukungan untuk menentukan keputusan terbaik [9]. Penelitian Pemetaan Pemasaran UMKM Kuliner Singkong berlokasi di Cibadak, Banten menerapkan bagian SPK yaitu perhitungan AHP mendefenisikan peran SPK bagian pengambil keputusan ditemukan Thomas L. Saaty. Penggunaan pemodelan keputusan menguraikan masalah multi faktor atau multi kriteria [10].

Sistem digolongkan sebagai sistem absolut dengan sistem yang digambarkan secara fisik. Sistem dalam SPK bersifat abstrak yaitu kumpulan pemikiran atau ide-ide yang tidak kelihatan secara fisik. Pendukung keputusan dirancang secara empiris dari sejumlah fakta nyata sehingga dapat memberikan keputusan yang tepat [11]. Sistem Pendukung Keputusan (SPK) dirancang berdasarkan Analisa permasalahan didukung solusi atas kejadian suatu peluang [12]. Sistem yang dirancang merupakan aplikasi pengembangan CBIS (Computer Based Information Systems) dengan karakteristik fleksibel, interaktif, mudah beradaptasi, dibentuk untuk memberikan solusi atas masalah manajemen spesifik yang tidak terstruktur [13]. Penelitian ini bertujuan dapat membantu meningkatkan keuntungan perusahaan melalui strategi pemasaran dengan menggunakan metode AHP.

\section{METODE PENELITIAN}

Penelitian menentukan strategi pemasaran barang pada Dunia Dapur dengan metode Analytic Hierarchy Process, pengumpulan data dilakukan e-commerce Dunia Dapur. Penyelesaikan penelitian tersebut dibutuhkan beberapa tahapan dimulai dari studi pendahuluan berupa studi kelayakan, studi kepustakaan dan studi lapangan. Kerangka kerja penelitian ini dapat dilihat seperti pada Gambar 1. 


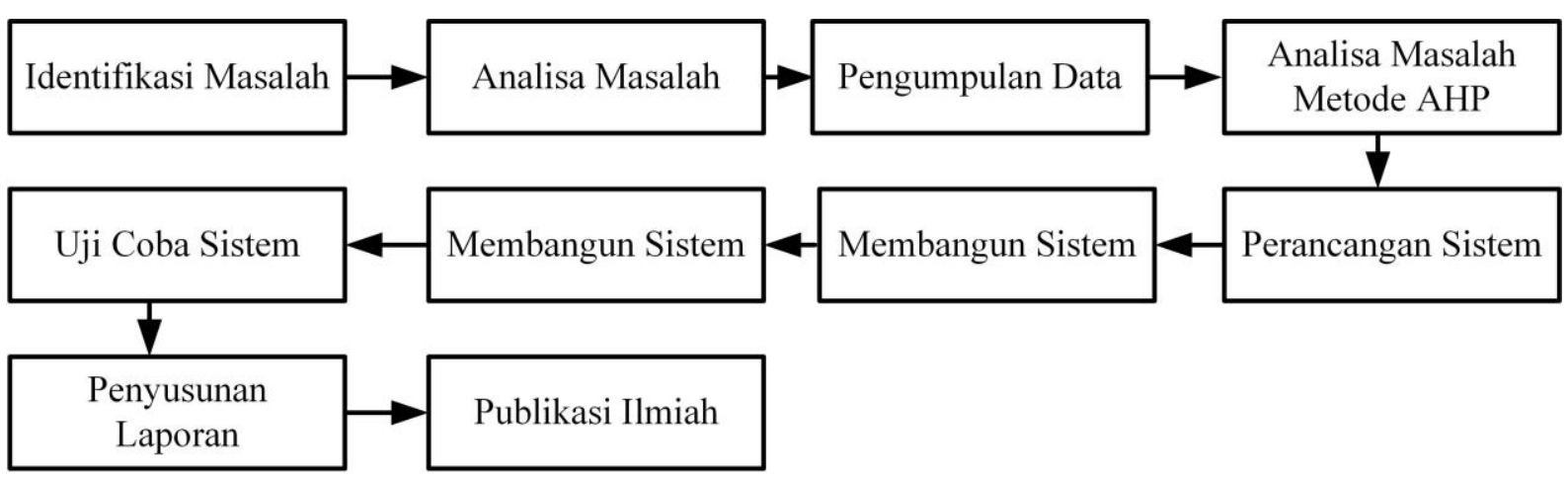

Gambar 1. Tahapan Penelitian

Uraian tahapan penelitian:

1. Identifikasi Masalah

2. Kerangka kerja penelitian ini dimulai dari identifikasi masalah yang terjadi yaitu dengan menentukan objek penelitian selankutnya merumuskan masalah dalam menentukan strategi pemasaran barang pada Dunia Dapur. Mengidentifikasi masalah terkait strategi pemasaran barang pada Dunia Dapur, sehingga dari penemuan permasalahan ini penulis dapat mencari solusi dari permasalahan tersebut.

3. Analisis Masalah

Pada tahap analisis masalah dilakukan kegiatan analisis secara rinci terhadap masalah yang telah didentifikasikan. Analisis pada sistem yang sedang berjalan tersebut, sistem dianalisa agar mampu mengatasi kekurangan dari sistem yang lama.

4. Pengumpulan Data

Data-data yang diperlukan dalam kebutuhan penelitian seperti strategi pemasaran barang, kriteria yang digunakan. Data yang diperoleh bersifat literatur melalui referensi buku, jurnal dan teoriteori secara tertulis dalam buku-buku ilmiah berkaitan dengan penentuan strategi pemasaran barang.

5. Analisis Data Dengan Metode AHP

Penggunaan metode pendukung kepastian sebuah kejadia berdasarkan metode AHP bertujuan menutupi kekurangan dari sistem dan lingkungan kedalam komponen agar saling berinteraksi satu sama lain di dalam sistem yang dibangun selanjutnya disatukan untuk mengukur dan memperoleh dampak dari komponen-komponen pembentuk sistem. Kriteria dan alternatif ditentukan berdasarkan kebutuhan sistem yang dibangun dengan ketentuan perbandingan berpasangan untuk berbagai persoalan, skala 1 sampai 9 merupakan skala terbaik.

Tabel 1. Skala Penilaian Perbandingan Berpasangan

\begin{tabular}{cl}
\hline $\begin{array}{c}\text { Intensitas } \\
\text { Kepentingan }\end{array}$ & \multicolumn{1}{c}{ Keterangan } \\
\hline 1 & Kedua elemen sama pentingnya \\
3 & Elemen yang satu sedikit lebih penting daripada elemen yang lainnya \\
5 & Elemen yang satu lebh penting dari pada elemen lainnya \\
7 & Satu elemen jelas lebih mutlak penting dari pada elemen lainya \\
9 & Satu elemen mutlak penting dari pada elemen lainnya \\
$2,4,6,8$ & Nilai-nilai Antara dua nilai pertimbangan yang berdekatan \\
Kebaikan & Jika aktivitas i mendapat satu angka dibandingkan dengan aktivitas j, maka i \\
& memiliki nilai kebalikannya dibandingkan dengan i \\
\hline
\end{tabular}

Setelah pengumpulan data selanjutnya analisis terhadap data:

1) Membuat Hirarki

Defenisi permasalahan pada awal pembentukan hirarki agar mencapai solusi yang diinginkan, penyusunan hierarki dalam AHP yaitu membentuk tingkatan penyelesaian permasalahan secara 
keseluruhan pada level teratas.

2) Penilaian kriteria dan alternatif

Melakukan penilaian terhadap kriteria dan alternatif dilakukan dengan perbandingan berpasangan dengan skala yang ditentukan dalam menyelesaikan permasalahan menggunakan tabel sesuai ketentuan AHP.

3) Synthesis of priority

Melakukan perbandingan berpasangan dari data, memperoleh data prioritas dengan total jumlah nilai-nilai dari setiap kolom pada matrik dan membagi setiap nilai dari kolom dari total kolom normalisasi matriks.

4) Logical consistency

Menjumlahkan nilai-nilai dari setiap baris dan membaginya dengan jumlah elemen untuk mendapatkan nilai rata-rata. Synthesis of priority dilakukan dengan menghitung consistency index dan consistency ratio, Tabel 2.

Tabel 2. Daftar Indeks Random Konsistensi

\begin{tabular}{cl}
\hline Ukuran Matriks & Nilai IR \\
\hline 1,2 & 0 \\
3 & 0,58 \\
4 & 0,9 \\
5 & 1.12 \\
6 & 1,24 \\
7 & 1,32 \\
8 & 1,41 \\
\hline
\end{tabular}

5) Perancangan sistem

Perancangan terhadap sistem dibangun dengan memodelkan sistem menggunakan pemodelan Unified Modeling Language, perancangan database dan juga perancangan interface.

6) Membangun sistem dan uji coba sistem

Sistem dibangun dengan melakukan pengkodean dengan bahasa pemrograman berdasarkan rancangan yang telah dibuat.

\section{HASIL DAN PEMBAHASAN}

Dari analisis data dan metode dapat ditentukan data kriteria dan nilai bobot untuk melakukan perhitungannya sehingga diperoleh data alternatif dengan nilai tertinggi. Penyelesaian permasalahan :

1. Memperjelas permasalah agar dapat menentukan solusi yang akan dicapai, lalu menyusun tingkatan hierarki dari permasalahan yang muncul dan menentukan capaian tujuan yang merupakan sasaran sistem secara keseluruhan pada level tertinggi.

2. Menentukan prioritas elemen

a. Penentuan prioritas elemen dilakukan pada tahap awal yaitu membuat perbandingan pasangan, dari setiap komponen elemen secara berpasangan sesuai data kriteria yang ditentukan.

b. Matriks perbandingan berpasangan dalam AHP dibuat dengan jenis bilangan dalam bentuk merepresentasikan kepentingan relative dari suatu komponen terhadap komponen lainnya.

3. Sintesis

Pertimbangan-pertimbangan terhadap perbandingan berpasangan dilakukan untuk memperoleh keseluruhan prioritas sintesis:

a. Menjumlahkan nilai-nilai dari setiap kolom pada matrik.

b. Membagi setiap nilai dari kolom dengan total kolom yang bersangkutan untuk memperoleh normalisasi matriks.

c. Menjumlahkan nilai-nilai dari setiap baris dan membaginya dengann julah elemen untuk mendapatkan nilai rata-rata.

4. Mengukur konsistensi

Dalam pembuatan keputusan, penting untuk mengetahui seberapa baik konsistensi berdasarkan 
pertimbangan dengan konsistensi rendah:

a. Kalikan setiap nilai pada kolom pertama dengan prioritas relative elemen pertama, nilai pada kolom kedua dengan prioritas relative elemen kedua, dan seterusnya

b. Jumlahkan setiap baris.

c. Hasil dari penjumlahan baris dibagi dengan elemen prioritas relative yang bersangkutan.

d. Jumlahkan hasil bagi diatas dengan banyaknya elemen yang ada hasilnya disebut $\lambda$ maks.

5. Hitung Consistency Index $(\mathrm{CI})$ dengan rumus $\mathrm{CI}=(\lambda$ maks-n $) / \mathrm{n}, \mathrm{n}=$ banyaknya elemen.

6. Hitung Rasio Konsistensi/Consistency Rastio $(\mathrm{CR})$ dengan rumus $\mathrm{CR}=\mathrm{CI} / \mathrm{RC}, \mathrm{CR}=$ Consistency Ratio. CI = Consistency Index, IR = Indeks Random Consistency.

7. Memeriksa konsistensi hierarki. Jika nilainya lebih dari $10 \%$, maka penilaian data judgement harus diperbaiki. Namun jika rasio konsistensi (CI/IR) kurang atau sama dengan 0,1, maka hasil perhitungan bisa dinyatakan benar.

Tahapan perancangan SPK metode AHP penentuan strategi pemasaran barang:

1. Mendefinisikan masalah dan tujuan yang diinginkan. Masalah yang muncul adalah bagaimana untuk menentukan strategi pemasaran barang yang sesuai dengan keadaan internal dan eksternal perusahaan.

2. Pengelompokkan kriteria-kriteria menjadi sebuah hirarki. Kriteria-kriteria yang mempengaruhi di dalam pengambilan keputusan penentuan strategi pemasaran barang.

3. Menentukan kriteria dan tingkat kepentingan dalam penentuan strategi pemasaran barang.

1) Kriteria

Kriteria penentuan stategi pemasaran terdiri dari 6 kelompok kriteria yaitu Managerial Capabilities, Customer Linking Capabilities, Market Innovation Capabilities, Human Resource Assets, Capabilities in Product Distribution, dan Reputational Assets.

Tabel 3. Kode Kriteria - Sub Kriteria

\begin{tabular}{ll}
\hline Kode & \multicolumn{1}{c}{ Kriteria } \\
\hline C01 & Kondisi Finansial Capabilities \\
C02 & Manajemen SDM yang Efektif \\
C03 & Manajemen Operasi yang Baik \\
& Customer Linking Capabilities \\
C04 & Layanan Terhadap Konsumen \\
C05 & Hubungan dengan Key Target Customer \\
C06 & Memahami Kebutuhan Konsumen \\
C07 & Hubungan dengan Konsumen \\
C08 & Pembinaan Hubungan dengan Konsumen \\
& Market Innovation Capabilities \\
C09 & Kemampuan Meluncurkan Produk Baru \\
C10 & Proses Pengembangan Produk yang Efektif \\
& Human Resource Asset \\
C11 & Tingkat Kepuasan Kerja Karyawan \\
C12 & Tingkat Retensi Karyawan \\
& Capabilities In Product Distribution \\
C13 & Hubungan Dengan Reseller \\
C14 & Mempertahankan Reseller Terbaik \\
C15 & Memberikan Value Terhadap Reseller \\
C16 & Tingkat Dukungan Terhadap Reseller \\
& Reputational Asset \\
C17 & Brand dan Reputasi \\
C18 & Kredibilitas \\
\hline &
\end{tabular}




\section{2) Alternatif}

Penentuan strategi pemasaran barang pada Dunia Dapur, alternatif strategi pemasaran barang yang digunakan adalah:

a. Cost Leadership Strategy (Alternatif 1)

Perusahaan bertujuan untuk menjadikan harga yang lebih rendah dari pesaing tanpa mengurangi keuntungan. Strategi ini menekankan pada efisiesi. Produk standar tanpa tambahan apapun yang dapat diproduksi pada biaya yang relatif rendah dan dapat tersedia bagi seluas mungkin pelanggan. Strategi ini terkait dengan strategi distribusi yang mampu menyediakan distribusi produk seluas mungkin. Strategi promosi yang sering digunakan meliputi upaya menyembunyikan fitur-fitur produk yang berbiaya rendah. Keberhasilan strategi ini membutuhkan pertimbangan keunggulan market share yang mampu mengakses bahan baku, komponen, tenaga kerja, dan input penting lainnya.

b. Differentiation Strategy (Alternatif 2)

Perusahaan berusaha untuk menjadi beda dari perusahaan lainnya di dalam industri yang sama. Perbedaan bisa pada produk yang dihasilkan. Diferensiasi meliputi penciptaan suatu produk yang unik. Keunikan fitur atau manfaat yang akan memberikan nilai superior bagi pelanggan akan menjamin keberhasilan strategi diferensiasi. Dalam strategi diferensiasi, terdapat beberapa syarat sukses yang harus dimiliki oleh perusahaan, yaitu:

1) Kekuatan dalam riset dan pengembangan.

2) Keahlian dalam rekayasa produk.

3) Kemampuan kreativitas yang tinggi.

4) Memiliki kerjasama yang baik dalam saluran distribusi.

5) Memiliki keahlian yang kuat dalam pemasaran.

6) Insentif sebagian besar didasarkan pada langkah-langkah subjektif.

7) Mampu berkomunikasi pentingnya karakteristik produk yang berbeda.

8) Pengelolaan secara terus-menerus terhadap stress dan inovasi.

9) Merekrut orang-orang yang memiliki keahlian tinggi dan kreatif.

c. Market Segmentation Strategies (Alternatif 3)

Digunakan untuk membangun keunggulan bersaing dalam suatu segmen pasar yang lebih sempit.

Strategi jenis ini ditujukan untuk melayani kebutuhan konsumen yang tidak dipengaruhi oleh harga.

Kriteria yang digunakan dalam sistem pendukung keputusan ini terdiri dari 18 kriteria serta tingkat kepentingan masing-masing kriteria maka matriks perbandingan berpasangan. Cara pengisian elemen-elemen matrik:

1) Elemen kriteria $[i, j]=1$, dimana $i=1,2,3, \ldots, n$ dan $j=1,2,3, \ldots, n$. Untuk penelitian ini $n=4$.

2) Elemen matriks segitiga atas adalah sebagai masukan.

Angka 1 pada C01 dan C01, menggambarkan tingkat kepentingan yang sama antara C01 dengan C01. Sedangkan angka 2 pada kolom C03 baris C01 menunjukkan C01 memiliki nilai pertimbangan yang berdekatan dengan C03 dan seterusnya. Angka 0.333 pada kolom C01 baris C03 merupakan hasil perhitungan dari 1/nilai pada kolom C03 baris C01. Angka-angka yang lain diperoleh dengan cara yang sama. Penyederhanaan Matriks Kriteria, semua hasil perbandingan berpasangan disintesis (disederhanakan). Dalam penyederhanaan matriks, data setiap kriteria diambil dari matriks kriteria berpasangan lalu setiap kolom akan dijumlahkan.

Nilai 0.1516 pada $\mathrm{C} 01$ baris $\mathrm{C} 01$ diperoleh dari nilai total dari C01 sedangkan bobot prioritas atau vector eigen diperoleh dari penjumlahan nilai setiap baris dibagi dengan jumlah kriteria. Sedangkan bobot prioritas atau vector eigen diperoleh dari penjumlahan nilai setiap baris dibagi dengan jumlah kriteria.

Nilai konsistensi (CM) pada baris C01 yaitu 23.035 merupakan hasil perkalian matriks, dikalikan dengan matriks pada kolom Bobot prioritas lalu dibagi dengan Bobot Prioritas baris C01 (0.168) dengan cara: 
$((1 * 0.168)+(2 * 0.103)+(3 * 0.095)+(3 * 0.08)+(4 * 0.076)+(5 * 0.065)+(5 * 0.063)+(6$ $* 0.051)+(6 * 0.043)+(7 * 0.046)+(8 * 0.036)+(8 * 0.034)+(9 * 0.027)+(9 * 0.022)+(1 * 0.028)+(1 *$ $0.028)+(3 * 0.017)+(2 * 0.017) /(0.168)=23.035$.

Menghitung rasio konsistensi untuk mengetahui apakah penilaian perbandingan kriteria bersifat konsisten. Berdasarkan jumlah kriteria yang telah ditentukan diatas, maka rasio indeks yang digunakan berdasarkan ordo matriks. Menghitung konsistensi index, digunakan $\mathrm{s} \lambda \max =\sum$ total $/ \mathrm{n}, \mathrm{CI}=(\lambda \max -$ $\mathrm{n}) /(\mathrm{n}-1), \mathrm{CR}=\mathrm{CI} / \mathrm{RI} . \lambda \max =(5.654+5.544+5.287+5.216+5.064) / 5=5.353, \mathrm{CI}=(5.353-5) / 5$ $-1=0.08825$. CR $=\mathrm{CI} / \mathrm{RI}=0.08825 / 1.12=0.07879$.

Karena nilai CR dibawah 0.10 maka matriks perbandingan kriteria dianggap konsisten. Jika hasil CR lebih besar dari 0.10 maka perbandingan kriteria dianggap tidak konsisten sehingga pembuatan matriks persamaan kriteria harus diulang. Selanjutnya setelah menemukan bobot prioritas kriteria, menetapkan nilai skala perbandingan alternatif berdasarkan masing-masing kriteria. Membentuk matriks perbandingan berdasarkan kriteria maka dicari bobot prioritas untuk perbandingan alternatif terhadap kriteria, Tabel 4.

Tabel 4. Matriks Perbandingan Alternatif - Kondisi Finansial

\begin{tabular}{lccc}
\hline \multicolumn{1}{c}{ Kode } & A01 & A02 & A03 \\
\hline A01 & 1 & 2 & 3 \\
A02 & 0,5 & 1 & 2 \\
A03 & 0,333 & 0,5 & 1 \\
$\sum$ & 1,833 & 3,5 & 6 \\
\hline
\end{tabular}

Angka 1 pada kolom A01 dan baris A01, menggambarkan tingkat kepentingan yang sama antara A01 dengan A01. Sedangkan angka 2 pada kolom A02 baris A01 memiliki nilai 2 menunjukkan bahwa A01 memiliki nilai pertimbangan yang berdekatan dengan A02 dan seterusnya. Angka 0.5 pada kolom A01 baris A02 merupakan hasil perhitungan dari 1/nilai pada kolom A02 baris A01 yaitu $(1 / 2=0.5)$ sedangkan angka-angka yang lain diperoleh dengan cara yang sama. Sedangkan nilai $\sum$ atau total diperoleh dari penjumlahan setiap kolom seperti pada tabel diatas sehingga nilai $\sum$ A01 memiliki total nilai 1.833 dan nilai $\sum$ dari $\mathrm{A} 02=3.5$ dan nilai $\sum \mathrm{A} 03=6$.

Tabel 5. Matriks Bobot Prioritas - Kondisi Finansial

\begin{tabular}{lccll}
\hline Kode & A01 & A02 & A03 & Bobot \\
\hline A01 & 0,545 & 0,571 & 0,5 & 0,539 \\
A02 & 0,273 & 0,286 & 0,333 & 0,297 \\
A03 & 0,182 & 0,143 & 0,167 & 0,164 \\
\hline
\end{tabular}

Nilai 0.545 pada kolom A01 baris A01 diperoleh dari nilai total $\left(\sum\right)$ dari kolom A01 baris A01 Tabel Matriks Perbandingan dibagi dengan nilai total $\left(\sum\right)$ kolom A01 baris A01 yaitu $1 / 1.833$.

Bobot prioritas atau vector eigen diperoleh dari penjumlahan nilai setiap baris dibagi dengan jumlah alternatif. Untuk bobot A01 diperoleh dengan $(0.545+0.571+0.5) / 3=5.386$ atau 5.39 . Perhitungan matriks perbandingan alternatif dan matrik bobot prioritas alternatif untuk setiap kriteria, dilakukan hal yang sama seperti perhitungan pada kriteria Kondisi Finansial. Menentukan Nilai Eigen Kriteria dan Alternatif, menemukan bobot dari masing-masing kriteria terhadap alternatif yang sudah ditentukan, pada Tabel 6.

Tabel 6. Perangkingan Alternatif

\begin{tabular}{llc}
\hline \multicolumn{1}{c}{ Alternatif } & Nilai & Ranking \\
\hline A01 - Cost Leadership Strategy & 0.59 & 1 \\
A02 - Differentiation Strategy & 0.274 & 2 \\
A03 - Market Segmentation Strategy & 0.136 & 3 \\
\hline
\end{tabular}


Langkah selanjutnya adalah mengalikan bobot prioritas (Vektor Eigen) dari setipmasing kriteria yang diambil dengan bobot dari masing-masing alternatif, kemudian hasil perkalian tersebut dijumlahkan perbaris.Nilai bobot prioritas (Vector Eigen) untuk setiap kriteria diperoleh dari nilai bobot prioritas sedangkan nilai baris A01 kolom C01 (0.539) diambil dari bobot prioritas untuk kriteria C01. Nilai yang terdapat pada kolom nilai diperoleh dengan mangalikan matriks antara baris A01 dengan vektor eigen. Maka nilai A01 diperoleh 0.59 merupakan perhitungan dari $(0.539 * 0.168)$ $+(0.544 * 0.103)+(0.648 * 0.095)+(0.656 * 0.08)+\ldots+(0.62 * 0.028)+(0.416 * 0.028)+(0.584 *$ $0.017)+(0.735 * 0.017)=0.59$. Ranking Alternatif, berdasarkan nilai Eigen kriteria dan alternatif dari strategi pemasaran barang yang cocok dengan kebutuhan diperoleh,

Berdasarkan perhitungan Differentiation Strategy memiliki nilai preferensi 0.59, sedangkan Cost Leadership Strategy memiliki nilai preferensi 0. 274, dan Market Segmentation Strategies nilai preferensi sebesar 0.136. Dapat disimpulkan bahwa alternatif yang berada di peringkat atas adalah Cost Leadership Strategy diberikan nilai 0.59. Dalam strategi ini Dunia Dapur berusaha menekan biaya produksi, sehingga laba bersih dapat menguntungkan yang akan meningkatkan angka penjualan dan market share.Implementasi dari pendukung keputusan menentukan strategi pemasaran metode Analytic Hierarchy Process:

\section{Halaman Utama}

Halaman utama sistem merupakan halaman yang berisi menu-menu yang berfungsi untuk memanggil halaman pengolahan data. Menu-menu tersebut terdiri dari menu Alternatif, menu Kriteria, menu Nilai Bobot Kriteria, menu Nilai Bobot Alternatif, menu Perhitungan, menu Hasil Ranking serta Logout.

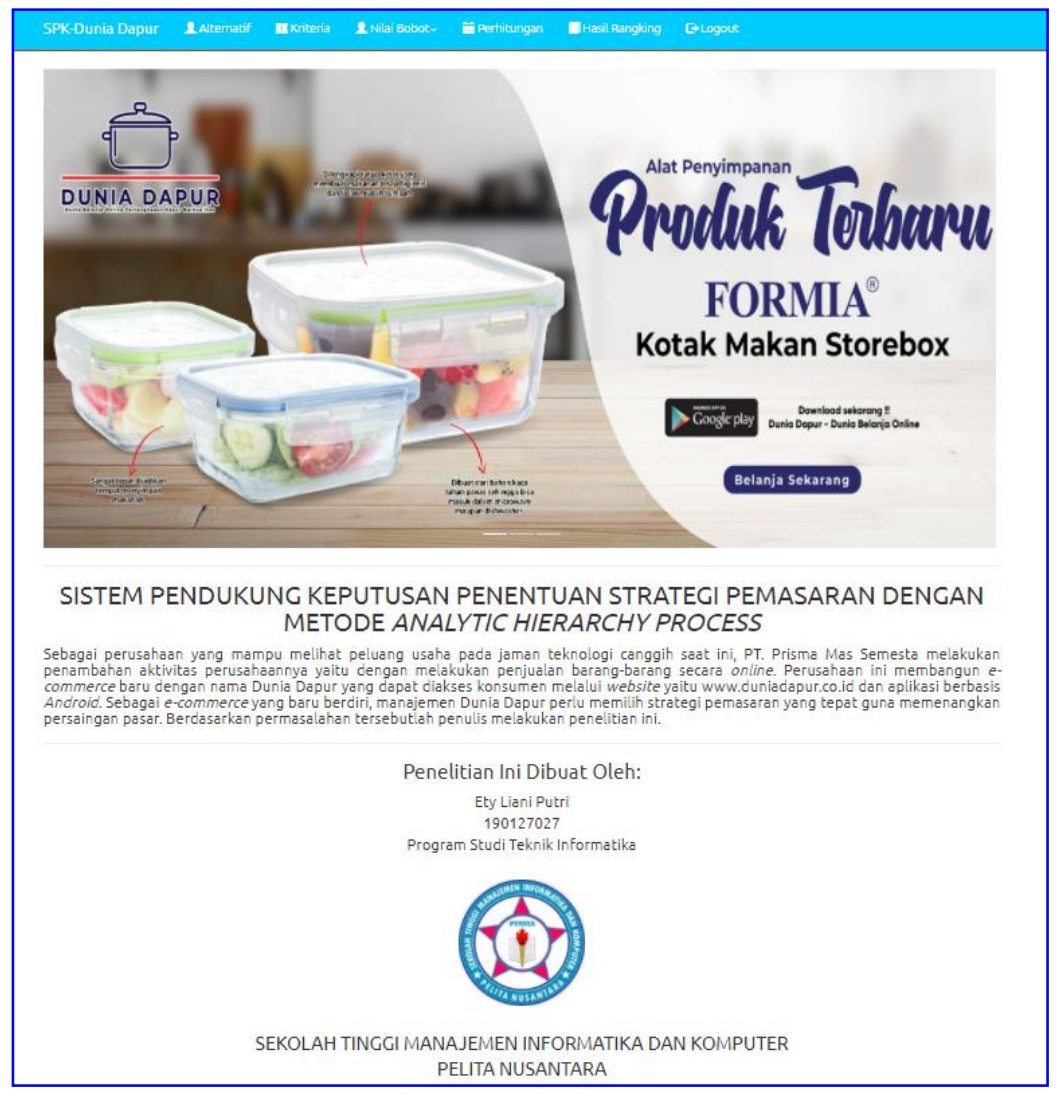

Gambar 2. Halaman Utama

2. Halaman Data Alternatif

Halaman data alternatif digunakan untuk pengolahan data alternatif. Administrator dapat menambah mengubah serta menghapus data alternatif, Gambar 3. 


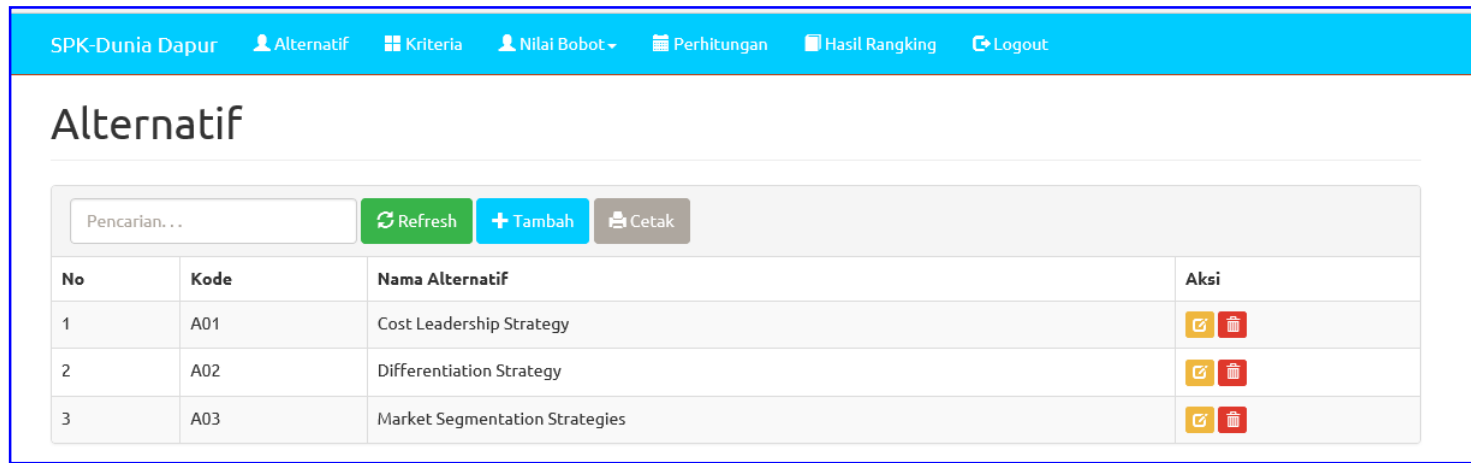

Gambar 3. Halaman Daftar Data Alternatif

\section{Halaman Data Kriteria}

Halaman data kriteria digunakan administrator untuk melakukan pengolahan data kriteria sebagai standar dalam penentuan strategi pemasaran. Pada halaman ini administrator dapat menambah data kriteria, mengubah data kriteria serta menghapus data kriteria, Gambar 4.

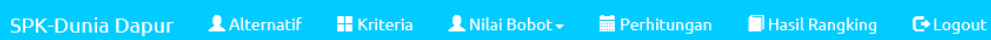

\section{Kriteria}

\begin{tabular}{|c|c|c|c|c|}
\hline \multicolumn{2}{|c|}{ Pencarian... } & ERefresh & \multirow[t]{2}{*}{ + Tambah GCetak } & \multirow[b]{2}{*}{ Aksi } \\
\hline No & Kode & Nama Kriteria & & \\
\hline 1 & C01 & \multicolumn{2}{|l|}{ Kondisi Finansial } & 匹圆 \\
\hline 2 & $\mathrm{C02}$ & \multicolumn{2}{|c|}{ Manajemen SDM yang Efektif } & 口目 \\
\hline 3 & $\mathrm{C} 03$ & \multicolumn{2}{|c|}{ Manajemen Operasi yang Baik } & 四面 \\
\hline 4 & $\mathrm{C} 04$ & \multicolumn{2}{|c|}{ Layanan Terhadap Konsumen } & 四面 \\
\hline 5 & $\mathrm{C05}$ & \multicolumn{2}{|c|}{ Hubungan dengan Key Target Customer } & 口面 \\
\hline 6 & $\mathrm{C} 06$ & \multicolumn{2}{|c|}{ Memahami Kebutuhan Konsumen } & 四面 \\
\hline 7 & $\mathrm{C} 07$ & \multicolumn{2}{|c|}{ Hubungan dengan Konsumen } & 四面 \\
\hline 8 & $\mathrm{C} 08$ & \multicolumn{2}{|c|}{ Pembinaan Hubungan dengan Konsumen } & 四面 \\
\hline 9 & $\cos$ & \multicolumn{2}{|c|}{ Kemampuan Meluncurkan Produk Baru } & 口臬 \\
\hline 10 & C10 & \multicolumn{2}{|c|}{ Proses Pengembangan Produk yang Efektif } & 四鱼 \\
\hline 11 & $\mathrm{C} 11$ & \multicolumn{2}{|c|}{ Tingkat Kepuasan Kerja Karyawan } & 口面 \\
\hline 12 & $\mathrm{C} 12$ & \multicolumn{2}{|c|}{ Tingkat Retensi Karyawan } & 口血 \\
\hline 13 & $\mathrm{C} 13$ & \multicolumn{2}{|c|}{ Hubungan Dengan Distributor } & 口田 \\
\hline 14 & C14 & \multicolumn{2}{|c|}{ Mempertahankan Distributor Terbaik } & 匹臬 \\
\hline 15 & C15 & \multicolumn{2}{|c|}{ Memberikan Value Terhadap Distributor } & 匹目 \\
\hline 16 & C16 & \multicolumn{2}{|c|}{ Tingkat Dukungan Terhadap Distributor } & 四面 \\
\hline 17 & C17 & \multicolumn{2}{|c|}{ Brand dan Reputasi } & 四面 \\
\hline 18 & C18 & \multicolumn{2}{|l|}{ Kredibilitas } & 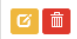 \\
\hline
\end{tabular}

\section{Gambar 4. Halaman Daftar Data Kriteria}

\section{Halaman Nilai Bobot Kriteria}

Halaman nilai bobot kriteria merupakan halaman untuk menentukan bobot untuk tiap kriteria. Pada halaman ini dilakukan perbandingan antar kriteria dengan memberi bobot, hingga akan terbentuk matriks bobot kriteria. Pada halaman ini administrator dapat menambah atau mengubah nilai perbandingan tiap kriteria, Gambar 5. 


\section{SPK-Dunia Dapur 2Alternatif HKriteria \& Nilai Bobot- A Perhitungan DHasil Rangking E. Logout}

\section{Nilai Bobot Kriteria}

\begin{tabular}{|c|c|c|c|c|c|c|c|c|c|c|c|c|c|c|c|c|c|c|}
\hline \multicolumn{6}{|c|}{ C01 - Kondisi Finansial } & \multicolumn{4}{|c|}{ 1-Sama penting dengan } & \multicolumn{5}{|c|}{ C01 - Kondisi Finansial } & $\checkmark$ & \multicolumn{3}{|c|}{ GUbah } \\
\hline Kode & c01 & $\mathrm{CO2}$ & $\mathrm{CO3}$ & CO4 & C05 & C06 & C07 & $\mathrm{COB}$ & $\cos$ & c10 & C11 & C12 & c13 & c14 & C15 & c16 & c17 & C18 \\
\hline c01 & 1 & 2 & 3 & 3 & 4 & 5 & 5 & 6 & 6 & 7 & 8 & 8 & 9 & 9 & 1 & 1 & 3 & 2 \\
\hline $\mathrm{CO2}$ & 0.5 & 1 & 1 & 2 & 2 & 4 & 3 & 3 & 2 & 2 & 5 & 7 & 5 & 5 & 3 & 6 & 6 & 2 \\
\hline $\mathrm{C03}$ & 0.333 & 1 & 1 & 2 & 3 & 4 & 1 & 1 & 2 & 5 & 3 & 1 & 4 & 5 & 3 & 7 & 3 & 9 \\
\hline C04 & 0.333 & 0.5 & 0.5 & 1 & 2 & 2 & 3 & 4 & 4 & 2 & 1 & 3 & 4 & 5 & 5 & 4 & 2 & 4 \\
\hline $\cos$ & 0.25 & 0.5 & 0.333 & 0.5 & 1 & 2 & 2 & 4 & 5 & 2 & 5 & 3 & 5 & 2 & 1 & 2 & 8 & 7 \\
\hline c06 & 0.2 & 0.25 & 0.25 & 0.5 & 0.5 & 1 & 2 & 3 & 3 & 1 & 4 & 3 & 3 & 4 & 7 & 8 & 2 & 3 \\
\hline $\mathrm{co7}$ & 0.2 & 0.333 & 1 & 0.333 & 0.5 & 0.5 & 1 & 3 & 2 & 3 & 4 & 2 & 4 & 3 & 4 & 5 & 3 & 6 \\
\hline $\cos$ & 0.167 & 0.333 & 1 & 0.25 & 0.25 & 0.333 & 0.333 & 1 & 4 & 2 & 1 & 3 & 4 & 2 & 3 & 5 & 6 & 2 \\
\hline C09 & 0.167 & 0.5 & 0.5 & 0.25 & 0.2 & 0.333 & 0.5 & 0.25 & 1 & 1 & 2 & 5 & 6 & 2 & 2 & 1 & 4 & 5 \\
\hline C10 & 0.143 & 0.5 & 0.2 & 0.5 & 0.5 & 1 & 0.333 & 0.5 & 1 & 1 & 5 & 3 & 2 & 4 & 6 & 2 & 2 & 2 \\
\hline C11 & 0.125 & 0.2 & 0.333 & 1 & 0.2 & 0.25 & 0.25 & 1 & 0.5 & 0.2 & 1 & 2 & 3 & 4 & 2 & 5 & 3 & 2 \\
\hline C12 & 0.125 & 0.143 & 1 & 0.333 & 0.333 & 0.333 & 0.5 & 0.333 & 0.2 & 0.333 & 0.5 & 1 & 2 & 3 & 4 & 1 & 3 & 6 \\
\hline C13 & 0.111 & 0.2 & 0.25 & 0.25 & 0.2 & 0.333 & 0.25 & 0.25 & 0.167 & 0.5 & 0.333 & 0.5 & 1 & 3 & 4 & 2 & 6 & 2 \\
\hline C14 & 0.111 & 0.2 & 0.2 & 0.2 & 0.5 & 0.25 & 0.333 & 0.5 & 0.5 & 0.25 & 0.25 & 0.333 & 0.333 & 1 & 2 & 4 & 2 & 3 \\
\hline C15 & 1 & 0.333 & 0.333 & 0.2 & 1 & 0.143 & 0.25 & 0.333 & 0.5 & 0.167 & 0.5 & 0.25 & 0.25 & 0.5 & 1 & 2 & 4 & 1 \\
\hline C16 & 1 & 0.167 & 0.143 & 0.25 & 0.5 & 0.125 & 0.2 & 0.2 & 1 & 0.5 & 0.2 & 1 & 0.5 & 0.25 & 0.5 & 1 & 4 & 5 \\
\hline C17 & 0.333 & 0.167 & 0.333 & 0.5 & 0.125 & 0.5 & 0.333 & 0.167 & 0.25 & 0.5 & 0.333 & 0.333 & 0.167 & 0.5 & 0.25 & 0.25 & 1 & 2 \\
\hline C18 & 0.5 & 0.5 & 0.111 & 0.25 & 0.143 & 0.333 & 0.167 & 0.5 & 0.2 & 0.5 & 0.5 & 0.167 & 0.5 & 0.333 & 1 & 0.2 & 0.5 & 1 \\
\hline
\end{tabular}

\section{by: Etyliani ๑ 2021}

\section{Gambar 5. Halaman Nilai Bobot Kriteria}

\section{Halaman Nilai Bobot Alternatif}

Halaman nilai bobot alternatif merupakan halaman untuk menentukan bobot alternatif untuk setiap kriteria. Pada halaman ini dilakukan perbandingan antar alternatif dari kriteria ditentukan, Gambar 6.

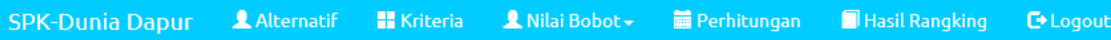

\section{Nilai Bobot Alternatif}

\begin{tabular}{|c|c|c|c|c|c|c|}
\hline C01 - Kondisi Finansial & & 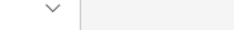 & & & & \\
\hline A01 - Cost Leadership Strategy & $\checkmark$ & 1-Sama penting dengan & $v$ & A01 - Cost Leadership Strategy & $\checkmark$ & GUbah \\
\hline Kode & & A01 & & A02 & & A03 \\
\hline A01 & & 1 & & 2 & & 3 \\
\hline A02 & & 0.5 & & 1 & & 2 \\
\hline A03 & & 0.333 & & 0.5 & & 1 \\
\hline
\end{tabular}

Gambar 6. Halaman Data Nilai Bobot Alternatif

\section{Halaman Perhitungan}

Halaman perhitungan akan menampilkan hasil perhitungan-perhitungan menggunakan metode AHP berdasarkan nilai bobot kriteria dan alternatif yang telah dimasukkan sebelumnya, Gambar 7 . 


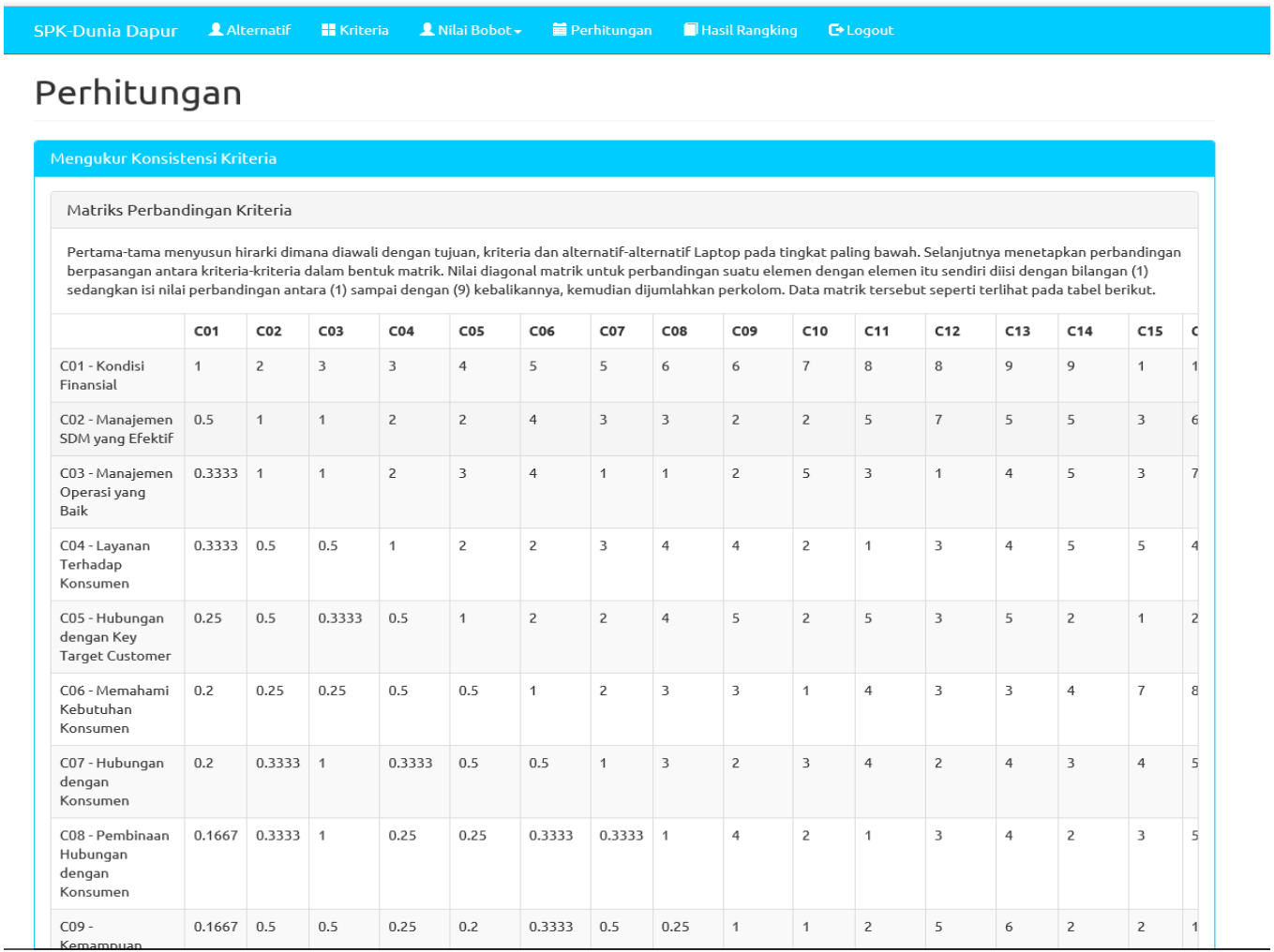

Gambar 7. Halaman Perhitungan AHP

\section{KESIMPULAN}

Sistem berbentuk kelihatan digambarkan secara dalam hal ini fisik adalah sistem digolongkan sebagai sistem alamiah dikembangkan manusia. Pengambilan keputusan didasarkan pada pengalaman berulang dipergunakan dalam memperhitungkan keadaan yang akan terjadi merupakan alasan pemecahan permasalahan dengan mencari solusi terbaik dari sejumlah alternatif. Untuk meningkatkan kinerja dan menyempurnakan sistem pendukung keputusan yang telah dibuat, dapat disimpulkan hasil penilaian yang yang dihasilkan sistem pendukung keputusan diharapkan dapat digunakan sebagai alat untuk menentukan strategi pemasaran yang akan diterapkan perusahaan. Nilai bobot dari data kriteria dan data alternatif mempengaruhi penilaian secara hierarki dengan mengambil nilai tertinggi dari perangkingan diputuskan menjadi metode strategi pemasaran barang terbaik.

\section{DAFTAR PUSTAKA}

[1] S. Yulia, G. Taufiq, and Y. Handrianto, "Model Sistem Pendukung Keputusan Penilaian Prestasi Marketing Agent Menggunakan Metode Analitycal Hierarchy Process ( AHP )," no. September 2021, pp. 75-85.

[2] W. M. I. Uhrowiyah, "Strategi Pengembangan Usaha Dan Kelayakan Finansial Agroindustri Susu Sapi Perah Di Kabupaten Jember Tesis," vol. 5, no. 2, pp. 189-198, 2021, [Online]. Available: https://sipora.polije.ac.id/id/eprint/5613.

[3] A. Sudradjat, M. Sodiqin, and I. Komarudin, "Penerapan Metode Analytical Hierarchy Process Terhadap Pemilihan Merek CCTV," J. Infortech, vol. 2, no. 1, pp. 19-30, 2020, doi: 10.31294/infortech.v2i1.7660.

[4] D. Rinova, P. D. Sandria, F. Ilmu, P. Universitas, and B. Lampung, “1 , 2 1,2,” vol. 1, no. 2 , pp. 147-160, 2021.

[5] A. A. S. Mutiara Halifah and S. Wulandari, "Usulan Perbaikan Komunikasi Pemasaran Voute dengan Metode Benchmarking dan Tool Analytical Hierarchy Process," e-Proceeding Eng., vol. 7, no. 2, pp. 6570-6576, 2020. 
[6] D. Lestari and A. S. R. Sinaga, "Penentuan Karyawan Kontrak Menjadi Karyawan Tetap PT. Timbang Deli Dengan Metode Analitycal Hierarchy Process (AHP)," J. Teknol., vol. 8, no. 2, pp. 27-37, 2018, [Online]. Available: www.jurnalteknologi.utm.my.

[7] Lamefa, "Strategy for the Development of Coffee Agroindustry in Kerinci Regency," J. AIP, vol. 8, no. 2, pp. 85-98, 2020.

[8] A. Info, "Analysis of Product Marketing Strategies using SWOT and AHP Methods at PT Raya Utama," vol. 8, no. 2, pp. 122-131, 2021.

[9] Frieyadie, "Metode AHP Sebagai Penunjang Keputusan Untuk Penilaian Kinerja Kerja Karyawan SPBU," J. TECHNO Nusa Mandiri, vol. 15, no. 1, pp. 63-68, 2018, [Online]. Available: http://ejournal.nusamandiri.ac.id/ejurnal/index.php/techno/article/view/840/pdf.

[10] FANDI AZIZ, "Sistem Penunjang Keputusan Penentuan Reward Bagi Mitra Terbaik Menggunakan Metode Simple Additive Weighting (SAW) (Studi Kasus : PT. Telkom Akses)," J. Fasilkom, vol. 11, no. 2, pp. 91-96, 2021, doi: 10.37859/jf.v11i2.2715.

[11] R. Fadillah, S. Dur, and H. Cipta, "Penerapan Metode Analytical Hierarchy Process dalam Menentukan Gaji Bonus Karyawan Pada PTPN III Sei Putih," J. Sains Mat. dan Stat., vol. 7, no. 2, pp. 73-84, 2021, doi: 10.24014/jsms.v7i2.12968.

[12] Y. H. Agustin, F. Nuraeni, and D. Kurniadi, "Implementasi AHP dan TOPSIS Untuk Proses Penentuan Pembimbing Tugas Akhir Mahasiswa," Nas. Teknol. Inf. Komun. dan Ind., vol. 12, no. 7 , pp. $70-145,2020$.

[13] T. R. Adianto, Z. Arifin, D. M. Khairina, G. Mahakam, and G. Palm, "Sistem Pendukung Keputusan Pemilihan Rumah Tinggal Di Perumahan Menggunakan Metode Simple Additive Weighting (Saw) (Studi Kasus : Kota Samarinda)," Pros. Semin. Ilmu Komput. dan Teknol. Inf., vol. 2, no. 1, pp. 197-201, 2017. 